\title{
Yield and composition of supercritical fluid extracts of different Lamiaceae herbs: Satureja hortensis L., Ocimum basilicum L. and Melissa officinalis L.
}

\author{
Kutta, G. ${ }^{1}$, Pluhár, Zs. ${ }^{1}$, Sárosi, Sz. ${ }^{1}$, Fülöp, A.L. ${ }^{1}$ \& Sándor, G. ${ }^{2}$ \\ 1Department of Medicinal and Aromatic Plants, Faculty of Horticultural Sciences, \\ Corvinus University of Budapest \\ 2Department of Pomology, Faculty of Horticultural Sciences, Corvinus University of Budapest
}

Summary: In our work the effectiveness of supercritical carbon dioxide extraction was studied on volatile and nonvolatile components of Lamiaceae herbs. The aim of our investigations was to determine the optimal extraction parameters yielding high amount of volatiles and nonvolatiles in a desirable composition. As plant materials, dried and powdered cude drugs of Satureja hortensis, Ocimum basilicum and Melissa officinalis were chosen. Pressure (8-50 MPa), temperature $\left(35-60^{\circ} \mathrm{C}\right)$, time (5-60 min) and the ratio of modifier (5-50\% methanol) of extraction were regulated. Results obtained by supercritical fluid extraction (SFE) were compared to that of the conventional extraction procedure, hydrodistillation (HD). In the case of Satureja hortensis, Ocimum basilicum and Melissa officinalis extract yield of SFE was comparable to the essential oil amount obtained by hydrodistillation from the same drug. Essential oil rich extracts were analysed by GC-FID, while extracts rich in nonvolatile compounds were analysed by HPLC. We have found that yield and quality of SFE extracts highly depend on the conditions of extraction.

Key words: supercritical fluid extraction, Lamiaceae, Satureja hortensis, Ocimum basilicum, Melissa officinalis, hydrodistillation, modifier, GC-FID, HPLC

\section{Introduction}

In the field of the research of medicinal and aromatic plants, great efforts are made in order to find and to isolate the active substances as well as to define their exact way of action. Volatile and nonvolatile compounds of the species belonging to the Lamiaceae family play an important role in phytotherapy, aromatherapy and as food additives, too. Summer savory (Satureja hortensis L.), basil (Ocimum basilicum L.) and lemon balm (Melissa officinalis L.) are aromatic herbs. They are used extensively to add a distinctive aroma and flavour to food. Fresh or dried leaves of them can be used as spices. Essential oil extracted from fresh leaves and flowers can be utilized as additives in food or in cosmetics as well as in pharmaceuticals.

Supercritical fluid extraction is an extraction method using supercritical fluids as extraction solvent instead of normal liquids. It has been shown that SFE with supercritical carbon dioxide can be far superior to conventional methods of extraction (such as liquid extaction or Soxhlet) in a variety of ways: speed of extraction, completeness of extraction, eliminating the solvent concentration step, simplified procedure, selectivity, reduced environmental hazard/ nontoxicity, cost savings, suitability for thermal sensitive samples, easiness of coupling to GC for on-line SFE/GC.

A solvent is considered to be a supercritical fluid when both its temperature and pressure equal or exceed the specific supercritical point. For $\mathrm{CO}_{2}$, the critical temperature and pressure are $31.1^{\circ} \mathrm{C}$ and $7.38 \mathrm{MPa}(=1050 \mathrm{psi})$, respectively.

Supercritical fluids possess almost similar density and solvating power to liquid organic solvents, but have extremely rapid diffusion characteristics and their viscosity is similar to those of the gases. The density of a gas can be varied and controlled by regulating pressure, temperature or both. The solvent capacity of supercritical $\mathrm{CO}_{2}$ can be increased or decreased by varying pressure and temperature. It should be noted that identical densities may be achieved at different pressure/ temperature relationship, but supercritical fluids at higher temperature and pressure have higher solvating power. An increase in the pressure and temperature enables supercritical $\mathrm{CO}_{2}$ to dissolve compounds of higher polarity (McNally \& Wheeler, 1988). If the elevation of pressure and temperature increases are not sufficient to dissolve the analyte, a small amount of modifier such as methanol, isopropanol, acetonitrile, water or benzene can be added to the supercritical $\mathrm{CO}_{2}$ to increase its solvating power as well as the polarity (Brennecke \& Eckert, 1989). Thus combination of pressure/temperature/ modifier control contributes to extract of a large variety of analytes by supercritical $\mathrm{CO}_{2}$ extraction (Schantz \& Chesler, 1986).

The hydrodistillation process has been traditionally used in the extraction of essential oils on a laboratory scale. In this work, we are intended to compare the efficiency of this process with its relationship to the volatile and nonvolatile composition of the supercritical $\mathrm{CO}_{2}$ extracts. 
Considering previous data obtained by SFE extraction of Satureja hortensis, Pluhar et al. (1996) concluded that the yields were lower than int he case of hydrodistillation. The highest value was obtained at $50{ }^{\circ} \mathrm{C}$ and $50 \mathrm{MPa}$, while the best, near natural volatile composition was reached at 10 MPà and $40{ }^{\circ} \mathrm{C}$.

The citral compounds could be extracted from lemon balm using SFE more efficiently and faster than with hydrodistillation (hydrodistillation lasted to $40 \mathrm{~min}$ to perform, while SFE needed only $20 \mathrm{~min}$ ). Increased amounts of citronellal, neral, neryl acetate, and caryophyllene oxide were found in hydrodistillation, while SFE yielded increased ratio of geranial and of caryophyllene. In addition, SFE yielded a greater total amount of compounds detected as compared to hydrodistillation (Rozzi et al., 2002).

Linalool is the main constituent in the basil extract. Despite the higher total yield of basil at $25.5 \mathrm{MPa}$, compared to pressure $17.2 \mathrm{MPa}$, the percentage of the major components (except 1.8-cineole), were less. It means that at higher pressures, additional components were extracted and the amount of extract changed substantially (Menaker et al., 2004).

\section{Materials and methods}

Dried leaves of summer savory (Satureja hortensis L.), basil (Ocimum basilicum L.) were grown and surveyed in Budapest, Hungary in 2006. Dried lemon balm (Melissa officinalis L.) was purchased from Herbária Zrt. (Budapest).

The plant (100 g of dried material of savory; $200 \mathrm{~g}$ of basil and of lemon balm) was subjected to hydrodistillation (HD) for 1,5 h, using Clevenger-type apparatus, according to the Hungarian Pharmacopoeia VII. (1986). The volatile distillates were analysed by GC-MS in the case of all species.

Supercritical fluid extraction (SFE): optimal parameters in the respect of extract amount and of the composition were investigated, where the pressure (8-50 MPa), temperature $\left(35-60^{\circ} \mathrm{C}\right)$, time $(5-60 \mathrm{~min})$ and modifier $(5-50 \%$ methanol $)$ were regulated. During pressure, time or temperature experiments the other two parameters were constant. In the case of modifier experiment, methanol was used between 5-50\% and 30-40-50 MPa (at constant $30 \mathrm{~min} 40^{\circ} \mathrm{C}$ ).

Isco SFX 2-10 type laboratory extractor with an Isco Model 260D pump module was used. The major features of the 260D pump include: high volume capacity $(260 \mathrm{ml})$, wide flow range with excellent accuracy and precision ( 11 to $90 \mathrm{ml} / \mathrm{min}$ ), high pressure range with excellent accuracy and precision (7500 psi), high corrosion resistance and wide solvent compatibility of components, smooth DC motor operation with stepper motor-like resolution and quartz locked speed control, pressure gradient and flow rate composition gradient programmability, eliminating the need for an external computer, 4-line LCD menu type displayer, memory for multiple methods (up to 99 total steps), ability of one controller to operate up to 3 ,D” series pumps simultaneously (or independently) and built-in modifier addition program (Myer et al, 1991). The SFE experiments were performed by carbon dioxide (purity $99.995 \%$ (w/w), supplied by Linde, Hungary).

In the case of the analysis of volatile compounds of savory, basil and lemon balm, GC-FID analysis was performed, using Agilent Technologies 6890N GC System: injector temperature: $250 \mathrm{C}$, split rate: $22,6: 1$; colonna: $\mathrm{HP}$ $5050 \%$ Phenyl Methyl Siloxane, length: $30 \mathrm{~m}$, diameter: $350 \mu \mathrm{m}$, film thickness: $0,25 \mu \mathrm{m}$; carrier gas: helium, linear velocity: $0,5 \mathrm{ml} / \mathrm{min}$, constans flow. Temperature program was as follows: start temperature of $50{ }^{\circ} \mathrm{C} / 0,5 \mathrm{~min}$, then $4{ }^{\circ} \mathrm{C} / \mathrm{min}$ till $150{ }^{\circ} \mathrm{C}$, kept up to $10 \mathrm{~min}$. Detector (FID) temperature was $250^{\circ} \mathrm{C}$. Volatile compounds were identified by comparing their retention time to those of the authentic standards. Standards were purchased at Sigma Aldrich.

GC-MS analysis was carried out by Agilent Technologies GC $6890 \mathrm{~N}$ using a HP-5 MS colonna, where detector was Agilent Technologies MS 5975. Colonna length: $30 \mathrm{~m}$, diameter: $250 \mu \mathrm{m}$, film thichness: $0,25 \mu \mathrm{m}$, carrier gas: helium, constans flow rate of $0,5 \mathrm{ml} / \mathrm{min}$. Injector and detector temperature: $250{ }^{\circ} \mathrm{C}$. Temperature program: $50{ }^{\circ} \mathrm{C}$ $10,5 \mathrm{~min}$, then $4{ }^{\circ} \mathrm{C} / \mathrm{min}$ - till $150^{\circ} \mathrm{C}$, then $12{ }^{\circ} \mathrm{C} / \mathrm{min}$ to $220^{\circ} \mathrm{C} / 10 \mathrm{~min}$.

Component identification was based on mass spectra (ionisation energy: $70 \mathrm{eV}$ ), NIST library, own volatile library as well as on retention time.

Nonvolatile compounds were analyzed at the HPLC laboratory of the Department of Pomology Corvinus University of Budapest. After methanol extraction, cleaning and filtering, $20 \mu \mathrm{l}$ of the extract was used for determination with a WATERS HPLC ( 717 plus auto-sampler, 1525 binary HPLC pump, 2487 dual absorbance detector, $350 \mathrm{~nm}$,

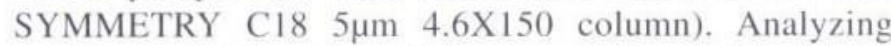
conditions: $2.5 \%$ acetic acid in water $(350 \mathrm{ml}), \mathrm{MeOH}(50$ $\mathrm{ml})$, acetonitrile $(100 \mathrm{ml})$ as mobile phase; flow-rate was 1 $\mathrm{ml} / \mathrm{min}$; column pressure was $1750 \pm 10 \mathrm{psi}$. The analysis was assisted by EMPOWER 2TM software (Meixner et al., 2007; Végvári \& Brunori, 2007).

Statistical analysis was performed by Statistica 7.0 program.

\section{Results}

The extract yield of SFE was comparable to the essential oil amount obtained by (hydrodistilled) HD from the same drug.

Yield and composition of SFE extracts were different, when comparing our data to the literature. In the case of summer savory the extraction was carried out using different pressures (between 8 and $30 \mathrm{MPa}$ at constant $40^{\circ} \mathrm{C}$ and $30 \mathrm{~min}$ ). In this interval an increasing tendency was observed regarding extraction yields. The highest value was detected at $27 \mathrm{MPa}(0.78 \mathrm{~g} / 100 \mathrm{~g}$ dry material $)$. In the temperature optimizing experiment (using different temperatures and constant $12 \mathrm{MPa}$ for $30 \mathrm{~min}$ ) the highest extract yield was detected at $50^{\circ} \mathrm{C}(0.37 \mathrm{~g} / 100 \mathrm{~g}$ dry material $)$ 
(Figure 1). When studying the effect of extraction time (at constant $12 \mathrm{MPa}$ and $40{ }^{\circ} \mathrm{C}$ ) the highest extract yield was produced during $55 \mathrm{~min}(0.50 \mathrm{~g} / 100 \mathrm{~g}$ dry material $)$. The effect of the extraction time was significant $(\mathrm{p}=0.00058)$. However, none of these results reached the amount of the destillate $(1.12 \mathrm{~g} / 100 \mathrm{~g} \mathrm{DW})$. In the volatile rich fraction of SFE extracts ratio of $\alpha$-terpinene was lower but the ratio of carvacrol higher than in the HD extract. According to the literature, $12 \mathrm{Mpa}$ and $60 \mathrm{~min}$ were recommended (Esquivel et al., 1999), however, based on our results, the parameters of $27 \mathrm{MPa}$ and $55 \mathrm{~min}$ seem to be more advantageous obtaining highest extract yields. During pressure optimization for nonvolatile compounds (applying pressures set between 30 and $50 \mathrm{MPa}$ ), the highest extract yield was measured at $43 \mathrm{MPa}$ $(1.00 \mathrm{~g} / 100 \mathrm{~g} \mathrm{DW})$. Quercetin was detected in each extract, the highest amount was observed at the pressure of $40 \mathrm{MPa}$ $(0.44 \mathrm{mg} / \mathrm{ml})$. At pressures of 40 and $45 \mathrm{MPa}$ eriodyctiol was also detected in the amounts of $1.336 \mathrm{mg} / \mathrm{ml}$ and 1.910 $\mathrm{mg} / \mathrm{ml}$, respectively. Luteolin was detected at pressure 35.40 and $45 \mathrm{MPa}$, with the highest value at $45 \mathrm{MPa}(1.06 \mathrm{mg} / \mathrm{ml})$. When using methanol as modifier solvent the obtained yields were higher at 40 and $50 \mathrm{MPa}$. For establishing the optimal extraction parameters, more experiments are need to be done. Simlarly to the simple SFE extracts quercetin was detected in each samples in higher amounts (up to $0,33 \mathrm{mg} / \mathrm{ml}$ at $40 \mathrm{MPa}$ and $40 \%$ methanol). Luteolin was measured in each sample, with the highest value at $40 \mathrm{MPa}$ and $40 \%$ methanol $(2.94$ $\mathrm{mg} / \mathrm{ml}$ ). Ursolic acid was detected in the highest quantity in our samples. The best value was reached at $50 \mathrm{MPa}$ and $10 \%$ methanol $(3129.15 \mathrm{mg} / \mathrm{ml})$. In the other samples was the ratio of ursolic acid prominent.

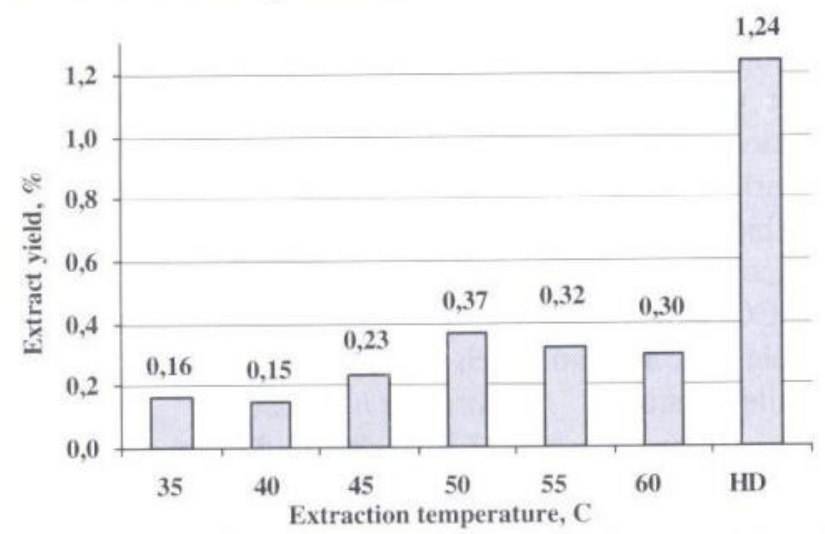

Figure 1 Optimization of extraction temperature in the case of Satureja hortensis (constant $10 \mathrm{MPa}$ and $40^{\circ} \mathrm{C}$ )

In the case of basil, the extraction was carried out using different pressures (between 8 and $30 \mathrm{MPa}$ at constant $40^{\circ} \mathrm{C}$ and $30 \mathrm{~min}$ ). In this interval, an increasing tendency was observed regarding extract yields. The highest values were detected at the pressure of $20 \mathrm{MPa}(0.31 \mathrm{~g} / 100 \mathrm{~g}$ dry material) and of $27 \mathrm{MPa}(0.39 \mathrm{~g} / 100 \mathrm{~g} \mathrm{DW})$. In the temperature optimizing experiment (using different temperatures and constant $12 \mathrm{MPa}$ for $30 \mathrm{~min}$ ) the highest extract yield was detected at $50^{\circ} \mathrm{C}(0.30 \mathrm{~g} / 100 \mathrm{~g}$ dry material $)$. When studying the extraction time (at constant $12 \mathrm{MPa}$ and $40^{\circ} \mathrm{C}$ ) the highest extract yield was produced during $40 \mathrm{~min}(0.33$ $\mathrm{g} / 100 \mathrm{~g}$ dry material). However, none of these results reached the amount of the destillate $(0.67 \mathrm{~g} / 100 \mathrm{~g} \mathrm{DW})$. In the volatile rich fraction of SFE extracts ratio of linalool and estragol was lower then in the distilled essential oil. According to the literature, $12 \mathrm{MPa}, 30 \mathrm{~min}$ and $40^{\circ} \mathrm{C}$ were previously recommended (Consuelo Diaz-Maroto et al., 2002), however, based on our results, the parameters of 11 $\mathrm{MPa}, 50^{\circ} \mathrm{C}$ and $40 \mathrm{~min}$ seem to be more advantageous obtaining higher extract yields. During pressure optimization for nonvolatile compounds (applying pressures set between 30 and $50 \mathrm{MPa}$ ), the highest extract yield was measured at 40 $\mathrm{MPa}(0.71 \mathrm{~g} / 100 \mathrm{~g} \mathrm{DW}$ ) (Figure 2). Luteolin was detected in each extract, the highest amount was observed at the pressure of $45 \mathrm{MPa}(105.99 \mathrm{mg} / \mathrm{ml})$. At pressures of 35 and $45 \mathrm{MPa}$ ursolic acid was also detected in the amounts of 161.23 $\mathrm{mg} / \mathrm{ml}$ and $153.51 \mathrm{mg} / \mathrm{ml}$, respectively. When using methanol as modifier solvent the obtained yields were higher at 40 and $50 \mathrm{MPa}(0.49$ and $0.43 \mathrm{~g} / 100 \mathrm{~g}$ dry material $)$. For establishing the optimal SFE parameters, more experiments are need to be done. Simlar to the simple SFE extracts luteolin was detected in each samples in rather different amounts $(0.49-100.71 \mathrm{mg} / \mathrm{ml})$. The highest quantity was measured at $40 \mathrm{MPa}$ with $40 \%$ methanol as modifier. The solvent modifier had no effect on the solubility of other nonvolatile compounds accumulated by the plants.

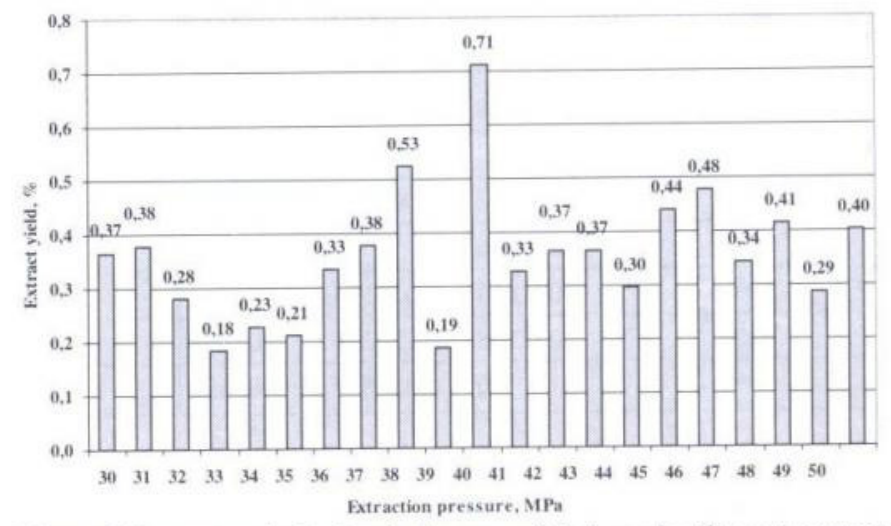

Figure 2 Pressure optimisation in the case of Ocimum basilicum (constant $40^{\circ} \mathrm{C}$ and $30 \mathrm{~min}$ )

In the case of time optimalization, significant correlation was detected between the time period and the ratio of linalool and estragol in the volatile fraction $(\mathrm{p}=0.000924$ and $\mathrm{p}=0.000049$ ).

In the case of lemon balm the same extraction parameters were tested. During pressure optimization (at constant $40^{\circ} \mathrm{C}$ and $30 \mathrm{~min}$ ) the highest extract yield could be measured at $28 \mathrm{MPa}(0.26 \mathrm{~g} / 100 \mathrm{~g} \mathrm{DW})$, and this value was much higher than that of the distilled oil $(0.06 \mathrm{ml} / 100 \mathrm{~g} \mathrm{DW})$. Within the volatile fraction of SFE extracts, the rattio of the main components (geranial, neral and citronellal) was lower than in the distilled essential oil. When optimizing extraction time (by constant $12 \mathrm{MPa}$ and $40^{\circ} \mathrm{C}$ ) the best result was detected after $30 \mathrm{~min}(0.11 \mathrm{~g} / 100 \mathrm{~g}$ dry material $)$, this value was almost twice higher than that of the HD yield. After 30 
min the amount of geranial increased considerably. After the $60 \mathrm{~min}$ extraction the ratio of caryophyllene oxide has also increased in the volatile fraction of SFE extracts. In the temperature optimalization the highest extract yield was detected at $40^{\circ} \mathrm{C}(0.11 \mathrm{~g} / 100 \mathrm{~g}$ dry material $)$. In general, the ratio of the main components in the SFE extracts was lower than within the essential oil of HD. Using SFE, the citral compounds can be extracted from lemon balm more

Table 1 Nonvolatile compounds in the case of Melissa officinalis $(\mathrm{mg} / \mathrm{ml})$ (constant $40^{\circ} \mathrm{C}$ and $30 \mathrm{~min}$ )

\begin{tabular}{|c|c|c|c|c|}
\hline Pressure (MPa) & Rosmarinic acid & Eryodictiol & Luteolin & Ursolic acid \\
\hline 30 & 0.002792 & 0 & 0 & 0 \\
\hline 35 & 0 & 0 & 0 & 0 \\
\hline 40 & 0.00431 & 0 & 0 & 0 \\
\hline 45 & 0.001208 & 0 & 0 & 3.060052 \\
\hline 50 & 0.003012 & 0 & 0 & 0.63885 \\
\hline \multicolumn{5}{|c|}{ Methanol $(\%)(30 \mathrm{MPa})$} \\
\hline $10 \%$ & 0.005898 & 0 & 0 & 0 \\
\hline $20 \%$ & 0 & 0 & 0 & 0 \\
\hline $30 \%$ & 0 & 0 & 0 & 0 \\
\hline $40 \%$ & 0 & 0.007482 & 0.002424 & 0 \\
\hline $50 \%$ & 0 & 0 & 0 & 0 \\
\hline \multicolumn{5}{|c|}{ Methanol (\%) (40 MPa) } \\
\hline $10 \%$ & 0 & 0 & 0 & 0 \\
\hline $20 \%$ & 0.012455 & 0.041528 & 0 & 0 \\
\hline $30 \%$ & 0 & 0.279067 & 0.013724 & 0 \\
\hline $40 \%$ & 0 & 0 & 0.00545 & 0 \\
\hline $50 \%$ & 0.024308 & 0 & 0 & 0 \\
\hline \multicolumn{5}{|c|}{ Metanol (\%) (50 MPa) } \\
\hline $10 \%$ & 0 & 0.007243 & 0.001236 & 0 \\
\hline $20 \%$ & 0.029946 & 0 & 0 & 0 \\
\hline $30 \%$ & 0.021614 & 0.024114 & 0.004811 & 0 \\
\hline $40 \%$ & 0.037738 & 0.259294 & 0.03229 & 0 \\
\hline $50 \%$ & 0 & 0.037559 & 0.00859 & 0 \\
\hline
\end{tabular}

efficiently and faster than with hydrodistillation (hydrodistillation lasted to $40 \mathrm{~min}$, while SFE needed only $20 \mathrm{~min}$ ). Increased amounts of citronellal, neral, neryl acetate, and caryophyllene oxide were found in hydrodistillation, while SFE yielded increased proportion of geranial and caryophyllene. In addition, SFE yielded a greater total amount of compounds detected when compared to hydrodistillation (Rozzi et al., 2002). In the pressure optimalization for non-volatile compounds (between 30 and $50 \mathrm{MPa}$ ), high extract yields were measured at 31 and 45 MPa (0.31 and $0.40 \mathrm{~g} / 100 \mathrm{~g} \mathrm{DW})$, where the best value was obtained at $47 \mathrm{MPa}(0.749 \mathrm{~g} / 100 \mathrm{~g}$ DW). Highest amount of rosmarinic acid was observed at 30 and $50 \mathrm{MPa}(0.00028$ and $0.00030 \mathrm{ml} / \mathrm{mg}$ ) (Table1). Ursolic acid was measurable only at 45 and $50 \mathrm{MPa}(0.30601$ and $0.06389 \mathrm{ml} / \mathrm{mg})$. In the case of lemon balm, the modifier solvent had no significant effect on the solvent power, the extract yields were almost the same as in the case of SFE- $\mathrm{CO}_{2}$. The highest yields were obtained at $50 \mathrm{MPa}$ pressure applying methanol $(30 \%)$ as modifier
(0.48 ml/100g DW), at $30 \mathrm{MPa}$ applying methanol (5 and $30 \%)$ as modifier $(0.332$ and $0.32 \mathrm{ml} / 100 \mathrm{~g}$ dry material), and at $40 \mathrm{MPa}$ applying methanol $(30,40$ and $45 \%)$ as modifier ( $0.33 ; 0.33$ and $0.35 \mathrm{~g} / 100 \mathrm{~g}$ dry material). The composition of these extracts were various. Rosmarinic acid was detected in the highest amount at $30 \mathrm{MPa}$ pressure with $10 \%$ methanol as modifier $(0.00589 \mathrm{mg} / \mathrm{ml})$, at $40 \mathrm{MPa}$ with $50 \%$ methanol as modifier $(0.02431$ and $0.02995 \mathrm{mg} / \mathrm{ml})$ and at $50 \mathrm{MPa}$ with $20 \%$ methanol as modifier. Luteolin was detected in low quantity in all of these extracts. The highest amount of eriodictiol was obtained at $40 \mathrm{MPa}$ with $30 \%$ methanol as modifier $(0.27907 \mathrm{mg} / \mathrm{ml})$.

In the case of pressure optimalization, significant effect of the pressure was found on the amount of geranial $(\mathrm{p}=0.030617)$ and by applying modifer on the extract yield $(\mathrm{p}=0.000383)$.

\section{Conclusions}

It has been demonstrated that SFE can produce superior quality products characterized by the absence of artefacts and by a better reproduction of the original flavour or fragrance.

Concerning optimalization experiments, the main effects of the four optional parameters - pressure, temperature, time and modifier - were evaluated with relevance to the yield and to the composition of extracts. It was established that the effect of pressure with or without modifier was the most significant on the above mentioned characters. In some cases, the SFE extract yields reached or were higher than the amount of essential oil obtained by hydrodistillation. Regarding different temperatures of extraction, it can be concluded that the results failed to reach the essential oil level of HD. The effect of extraction time was not proven to be really significant in the case of basil and lemon balm. In few cases, similarly to the previous parameter, the yield of SFE extracts were higher than the essential oil amount of HD.

According to our results, the following conditions of SFE- $\mathrm{CO}_{2}$ can be determined as optimal parameters to obtain volatile or non-volatile-rich extracts:

Volatile fraction: $\quad$ Satureja hortensis: $27 \mathrm{MPa}, 50^{\circ} \mathrm{C}, 55 \mathrm{~min}$

Ocimum basilicum: $\quad 25-27 \mathrm{MPa}, 45-50{ }^{\circ} \mathrm{C}, 40-55 \mathrm{~min}$

Melissa officinalis: $\quad 13 \mathrm{MPa}, 40^{\circ} \mathrm{C}, 30 \mathrm{~min}$

Nonvolatile fraction: Satureja hortensis: $40-45 \mathrm{MPa}$

yield:

composition:

Ocimum basilicum:

yield:

composition:

Melissa officinalis:

yield:

composition:

$40-45 \mathrm{MPa}(10-50 \%$ methanol)

depends on the component

$35-45 \mathrm{MPa}$

$50 \mathrm{MPa}, 5-50 \%$ modifier, $40 \mathrm{MPa}, 40 \%$ modifier

$45-47 \mathrm{MPa}$

30-50 MPa, 5-50\% modifier,

The parameters determined can serve as a basis for higher scale extraction of Lamiaceae drugs. More research work is still necessary in all aspects related to the supercritical fluid extraction of essențial oils. 


\section{References}

Brennecke, J.F. and Eckert, C.A. (1989): Phase Equilibria for Supercritical Fluid Process Design. American Institute of Chemical Engineers. 35: 1409-1427.

Consuelo Díaz-Maroto, M., Soledad Pérez-Coello, M., Dolores Cabezudo, M. (2002): Supercritical carbon dioxide extraction of volatiles from species comparison with simultaneous distillationextraction. Journal of Chromarography A. 947:23-29.

Esquivel, M.M., Ribeiro, M.A., Bernardo-Gil M.G. (1999): Supercritical extraction of savory oil: study of antioxidant activity and extract characterization. Journal of Supercritical Fluids 14: 129-138.

McNally, M.E.P. and Wheeler, J.R. (1988): Increasing Extraction Efficiency in Supercritcal Fluid Extraction From Complex Matrices. Journal of Chromatography. 447: 53-63.

Meixner, Staehelin, Steinkeller, S., Gagnon, H., Ludwig-Müller, J., Végvári, G.,C. Vierheilig, H. (2007): Two defined alleles of the LRRGRESSHOFF, P.CH. receptor kinase GmNARK in supernodulating soybeam govern differing autoregulation of mycorrhization. Physiologia Plantarum 130(1):261-270.
Menaker, A.A., Kravets, M., Koel, M., Orav, A. (2004): Identification and characterization of supercritical fluid extracts from herbs. Comptes Rendus Chimie 7: 629-633.

Pharmacopoeia Hungarica VII. (1986): Medicina, pp. 227-228.

Pluhár, Zs., Németh, É., Bernáth, J., Héthelyi, É. (1996): Illóolaj tartalmú drogok szuprerkritikus extraktumainak analizise. Olaj, Szappan, Kozmetika 45: 70-74.

Rozzi, N.L., Phippen, W., Simon, J.E., Singh, R.K. (2002): Supercritical Fluid Extraction of Essential Oil Components from Lemon-Scented Botanicals, Lebensmittel-Wissenschaft- undTechnologie, 35: 319-324.

Schantz, M.M. and Chesler, S.N. (1986): Supercritical Fluid Extraction Procedure for the removal of Trace Organic Species form Solid Samples. Journal of Chromatography. 363: 397-401.

Végvári, G., Brunori, A. (2007): Variety and location influence on the rutin content of the grain of buckwheat (Fagopyrum esculentum Moench. and Fagopyrum tataricum Gaertn.) varieties grown in central and southern Italy. Advances in Buckwheat Research. (10): 349-357. 